\title{
AVALIAÇÃO DE FOSFATO EM REFRIGERANTES COMO POTENCIAL CAUSADOR DE HIPERFOSFATEMIA POR SOBRECARGA EXÓGENA DO ÍON POLIATÔMICO
}

\section{EVALUATION OF PHOSPHATE IN REFRIGERANTS AS A POTENTIAL CAUSE OF HYPERPHOSPHATEMIA BY EXOGENOUS OVERLOAD OF POLYATOMICION}

\author{
Adna Tamires da Silva Lima ${ }^{1}$, Daniel Ângelo Macena ${ }^{2}$, Vinicius Marques \\ Gomes $^{1}$

\footnotetext{
${ }^{1}$ Universidade do Oeste Paulista - UNOESTE. ${ }^{2}$ Universidade Virtual do Estado de São Paulo-UNIVESP.

E-mail: adnatata@hotmail.com
}

RESUMO - O refrigerante é um dos produtos mais consumidos no Brasil. Por conter íons de fosfato na composição, o descontrole da ingestão do mineral fósforo, pode causar a hiperfosfatemia. Diante disto, o objetivo foi avaliar fosfato em refrigerantes de diferentes tipos e investigar se adequados para ser ingerido conforme a recomendação diária com auxílio da técnica de espectrofotometria visível para bebidas não alcoólicas. Conforme os resultados, apenas o refrigerante do tipo guaraná apresentou estar de acordo com a legislação vigente, que permite até $0,07 \%$ de fosfato, e seguro para ingestão diária para adultos saudáveis. Já o refrigerante do tipo cola resultou em total desacordo com legislação e completamente inadequado para consumo. Portanto, órgãos fiscalizadores devem se atentar com outros fatores de riscos presentes na composição do produto por ser uma bebida muito consumida e com alto potencial causador de hiperfosfatemia.

Palavras-chave: Bebidas não alcoólicas; Eletrólito do corpo; Ligação química.

ABSTRACT - The soda is one of the most consumed products in Brazil. Because it contains phosphate ions in the composition, uncontrolled intake of the phosphorus mineral can cause hyperphosphatemia. Therefore, the objective was to evaluate phosphate in soft drinks of different types and to investigate if they are suitable to be consumed according to the daily recommendation with the aid of the visible spectrophotometry technique for non-alcoholic beverages. According to the results, only guaraná type soda has been in compliance with current legislation, which allows up to $0.07 \%$ phosphate, and safe for daily intake for healthy adults. Already the cola-type soda resulted in total disagreement with legislation and completely unsuitable for 
consumption. Therefore, regulatory agencies should be aware of other risk factors present in the composition of the product as it is a very consumed drink and with high potential that causes hyperphosphatemia.

Keywords: Non-alcoholic beverages; Body electrolyte; Chemical bond. 


\section{INTRODUÇÃO}

A produção de refrigerantes no Brasil, corresponde ao equivalente de $75 \%$ do setor de bebidas do país. Setor este, que quase não existe importação relacionado ao comércio exterior (BNDES, 2014).

De acordo com a Associação Brasileira das Indústrias de Refrigerantes e Bebidas não Alcóolicas (ABIR), tem-se que o refrigerante é considerado uma bebida não alcoólica, produzida industrialmente a partir de processos de carbonatação e adição de aromas, a fim de resultar em um produto saboroso e refrescante (WILLETT, 2017).

Conforme Silva et al. (2019), o refrigerante é um dos produtos mais consumidos no Brasil, perdendo apenas para os sucos, café, carne, arroz e feijão. Outro fator importante é que a Pesquisa de Orçamento Familiar (POF) já chegou a registrar um aumento de $400 \%$ na participação do produto não dietético nos domicílios pelos brasileiros.

Segundo Biggs et al. (2017), na composição dos refrigerantes podem conter o mineral fósforo na forma de fosfatos primários, fosfatos dibásicos e fosfatos tribásicos, considerados íons poliatômicos (Figura 1), relacionados ao controle da acidez da solução, oxidar metais e preservação ao natural do produto, respectivamente.

Figura 1. Molécula do íon poliatômico de fosfato

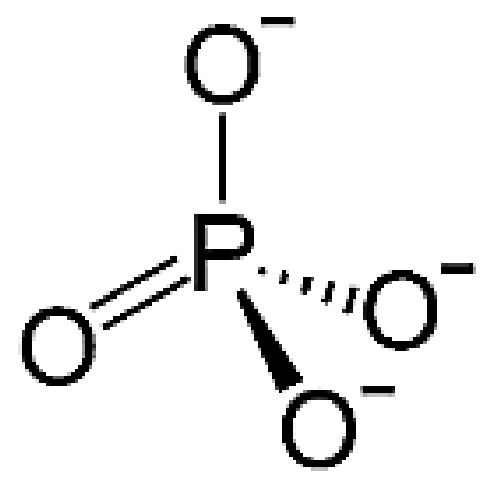

Fonte: (Mateo, 2012).

Para adultos saudáveis recomenda-se a ingestão diária de até $700 \mathrm{mg}^{-1} \mathrm{dl}^{-1}$ do mineral, no entanto, os pacientes com doença renal crônica (DRC) não deve ingerir mais de 3,5 mg. $\mathrm{dl}^{-1}$, pois os níveis séricos de fósforo pode aumentar em instantes seguido de uma refeição rica contendo o mineral (FELIX; MEDEIROS; MOLINA, 2018).

O descontrole da ingestão do mineral fósforo, principalmente por refrigerantes na forma de fosfatos, pode causar a hiperfosfatemia, definida como níveis plasmáticos ou séricos de fosfatos elevados, acima dos limites de normalidade, evidenciando uma sobrecarga exógena por ingestão oral em altas doses (SCHAEFER, 1994; ALONSO, 2015).

Desta forma, alguns problemas por lesões graves, como insuficiência renal crônica, hipoxemia, calcificação pulmonar, distúrbios cardiovasculares, hiperemia conjuntival, queratopatias e nefrocalcinose podem ser ocasionados devido à hiperfosfatemia (MOSTELLAR; TUTTLE, 1964; LOH; SAW; SETHI, 2010; BANSAL et al., 2014). Além disto, pode produzir sintomas gastrointestinais, como vômitos, diarreia e náuseas, dentre outras características clínicas encontradas conforme o distúrbio subjacente (SILVA; PINHEIRO; SOUTO, 2006).

Tais sintomas da hiperfosfatemia podem ser advindos de forma aguda e/ou crônica, na qual as causas agudas normalmente são contingentes e consecutivas ao aumento na absorção intestinal do fósforo ou desvios do mineral fósforo para o meio extracelular (Silva; Pinheiro; Souto, 2006; Shaman; Kowalski, 2016). Enquanto que a hiperfosfatemia crônica é procedente da diminuição de fósforo na excreção renal (PRINCE et al., 1982; ORIAS; MAHNENSMITH; PERAZELLA, 1999; MOE, 2008).

Por apresentar risco a saúde dos consumidores, este trabalho teve como objetivo, avaliar fosfato em refrigerantes de diferentes tipos, a fim de comparar com o órgão regulamentador, se está em conformidade com o valor máximo permitido e investigar se algum dos tipos de refrigerante é seguro para ser ingerido conforme a recomendação diária. 


\section{METODOLOGIA}

Segundo o Instituto Adolfo Lutz (1985), a determinação do teor de fosfato pode ser realizada em amostras de aditivos contendo pirofosfatos, tripolifosfatos, hexametafosfatos, etc., por meio de técnica de espectrofotometria na região do visível, na qual baseia-se na complexação do íons fosfato com vanado-molibdato de amônio. Metodologia proposta e utilizada no presente artigo pelo baixo custo e ser considerada de alta eficiência.

\subsection{AQUISIÇÃO DAS AMOSTRAS}

Foram adquiridas amostras de três tipos diferentes, a partir de supermercados da região de Presidente Prudente - SP, sendo tipo cola, laranja e guaraná, totalizando 9 amostras de refrigerante lata em conteúdo de $350 \mathrm{~mL}$ para ser analisadas em triplicata.

\subsection{PREPARO DA CURVA ANALÍTICA}

Foi preparada previamente a curva analítica de padrão de fosfato correspondente à relação gráfica entre os valores de concentração (eixo $X$ ) e absorbância (eixo $Y$ ) nas concentrações entre 0,02 e $0,15 \%$, unidade em \% obedecendo à legislação vigente que permite até $0,07 \%$ de fosfato em refrigerantes.

\subsection{PRÉ-TRATAMENTO DA AMOSTRAGEM}

Para o pré-tratamento, as amostras foram desgaseificadas com auxílio de um agitador magnético (Marca: Quimis, Modelo: $0261 \mathrm{M} 12$ ), sem necessidade de um valor de rotação específico por ser perceptível a amostra já não contém gás. Posteriormente, foi utilizada uma estufa de secagem (Marca: Olidef, Modelo: $\mathrm{CZ}$ ) em temperatura entre $103-105^{\circ} \mathrm{C}$ até secagem definitiva de água. Nesta etapa a secagem permaneceu na estufa por pelo menos 24 horas garantindo a secagem do conteúdo total de cada lata em cápsulas de porcelana.

\subsection{TRATAMENTO TÉRMICO}

Em seguida, todo o resíduo foi carbonizado em bico de Bunsen e depois levado imediatamente para um forno do tipo mufla a 550ㄷ (Marca: SP Labor, Modelo: SP1200), por 4 horas, a fim de mineralizar todo o resíduo deixando-o livre de matéria orgânica.

\subsection{TRATAMENTO QUÍMICO}

Após o resfriamento das cinzas, foi pesado $200 \mathrm{mg}$ de cada respectiva amostra e diluída em solução de ácido clorídrico $(\mathrm{HCl})$ 0,05 $\mathrm{M}$ e transferido quantitativamente para balão volumétrico de $100 \mathrm{~mL}$. No mesmo balão foi adicionado $25 \mathrm{~mL}$ do reagente vanado-molibdato de amônio como agente complexante, responsável pela reação, em cada balão e água purificada completando o volume até $o$ menisco. Por fim, procedeu a homogeneização e o aguardo de 10 minutos para a realização da leitura das amostras no espectrofotômetro.

\subsection{LEITURA DA CONCENTRAÇÃO DE FOSFATO NAS AMOSTRAS}

Conforme o método proposto, as leituras das amostras ocorreram em comprimento de onda a $420 \mathrm{~nm}$. A quantidade de fosfato correspondente foi determinada a partir da absortividade das amostras em espectrofotômetro visível (Marca: Quimis, Modelo: Q898DPT) com auxílio da equação previamente estabelecida na curva padrão de fosfato.

\section{RESULTADOS E DISCUSSÃO}

Conforme o gráfico 1 , o $R^{2}$ da curva analítica indica a porcentagem do quanto o modelo gráfico explica os valores observados (OLIVEIRA; LUSTOSA; SALES 2007). A propósito, pode variar entre 0 e 1 , o que garante nos resultados analíticos deste trabalho uma confiabilidade de aproximadamente $99,9 \%$.

Da Silva et al. (2013) obteve a mesma confiabilidade na curva analítica de fosfato, para práticas espectrofotométricas moleculares, variando concentrações entre 0,02 a $2 \mathrm{mg} . \mathrm{L}^{-1}$ com apenas quatro pontos. $\mathrm{O}$ que valida e assegura a questão do método 
proposto ser eficiente para determinação do íon fosfato em bebidas não alcoólicas.

Gráfico 1. Curva analítica para determinação de fosfato (\%) versus absorbância.

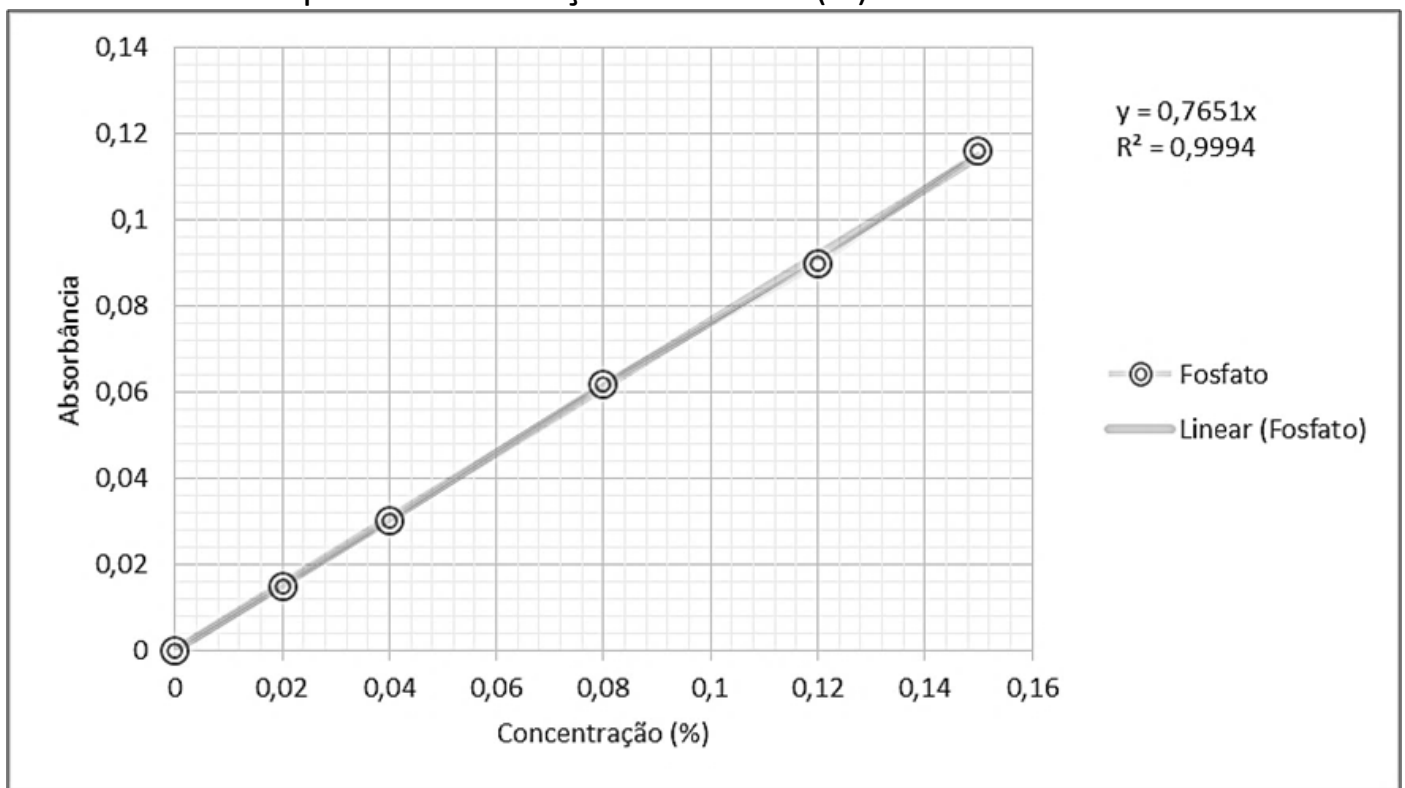

Fonte: $\mathrm{O}$ autor

Gráfico 2. Resultados analíticos da concentração de fosfato em refrigerante tipo guaraná, laranja e cola.

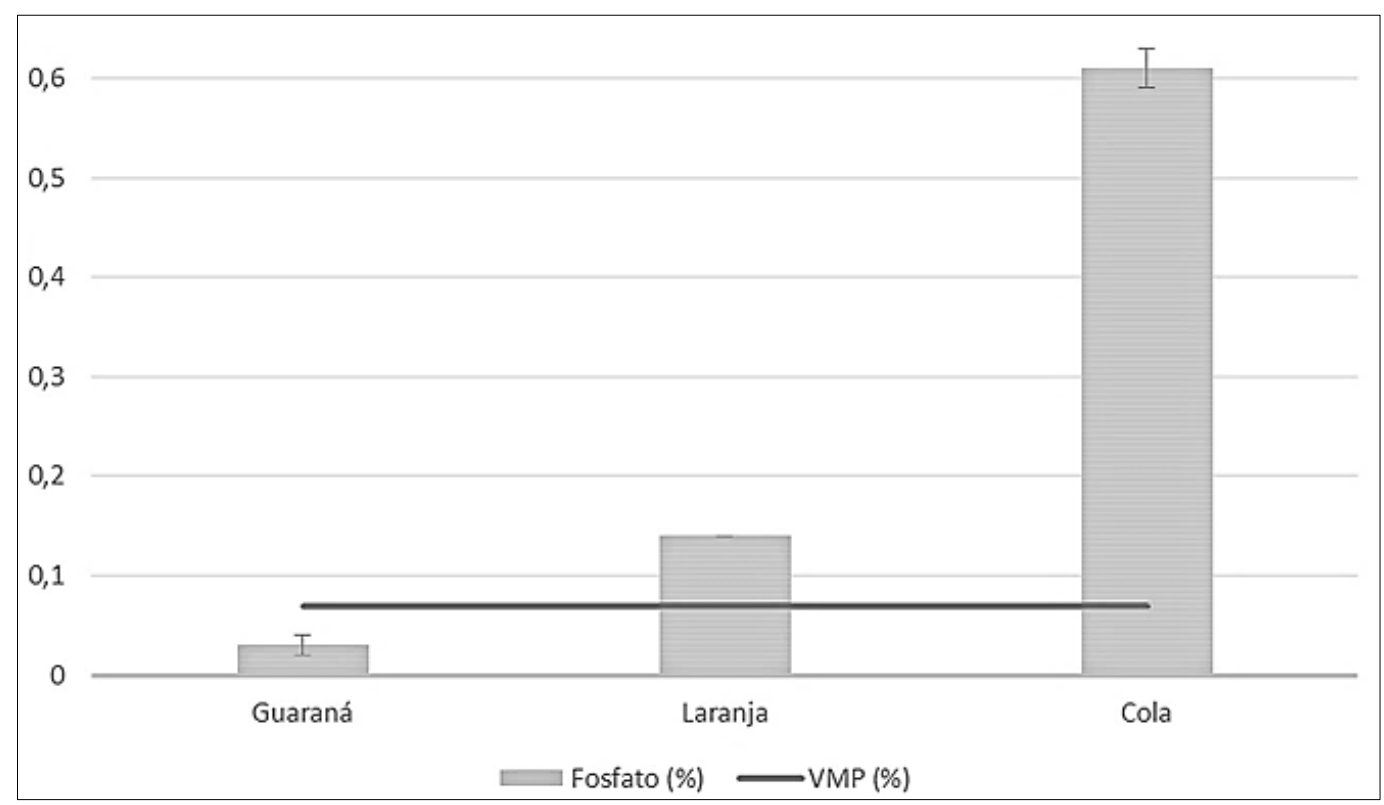

Fonte:O autor.

Nota: VMP = Valor Máximo Permitido

De acordo com a Agência Nacional de Vigilância Sanitária (ANVISA), o limite permitido de fosfato em refrigerantes é de $0,07 \%$ e o descumprimento aos termos desta Resolução constitui infração sanitária sujeitando os infratores às penalidades previstas na Lei no 6.437 , de 20 de agosto de
1977 e demais disposições aplicáveis (Brasil, 1977).

Levando em consideração os resultados das amostras (Gráfico 2) de guaraná, a média da concentração de fosfato foi de $0,03 \pm 0,01 \%$, o que percebe-se estar próximo da metade do VMP pela legislação. Relacionando os resultados dos refrigerantes 
do tipo laranja e cola, tem-se que estavam em total desacordo com o que o órgão regulamentador estabelece, pois o tipo laranja apareceu o dobro acima do VMP, 0,14 $\pm 0,00 \%$, enquanto que o tipo cola foi o que apresentou o pior resultado em se tratando da concentração do íon poliatômico fosfato em sua composição, apontando mais que oito vezes acima do $\operatorname{VMP}(0,61 \pm 0,02 \%)$.

Apesar de todos os possíveis ligantes orais de fósforo atualmente disponíveis no mercado, a restrição dietética deste mineral continua a ser uma pedra angular para a prevenção e tratamento da hiperfosfatemia. Uma restrição efetiva da ingestão dietética de fósforo requer a prescrição de uma ingestão moderada de proteína e consumo restrito de alimentos e bebidas rápidas. Pois, o fósforo adicionado durante o processamento de alimentos e produção de bebidas é uma fonte importante deste mineral devido à sua magnitude e alta biodisponibilidade (URIBARRI, 2007). Deste modo, esses refrigerantes após as condições experimentais dificulta a restrição efetiva da ingestão dietética já que são considerados produtos altamente consumidos diariamente.

Gráfico 3. Resultados comparativos ao recomendado de ingestão diária de fosfato para adultos saudáveis.

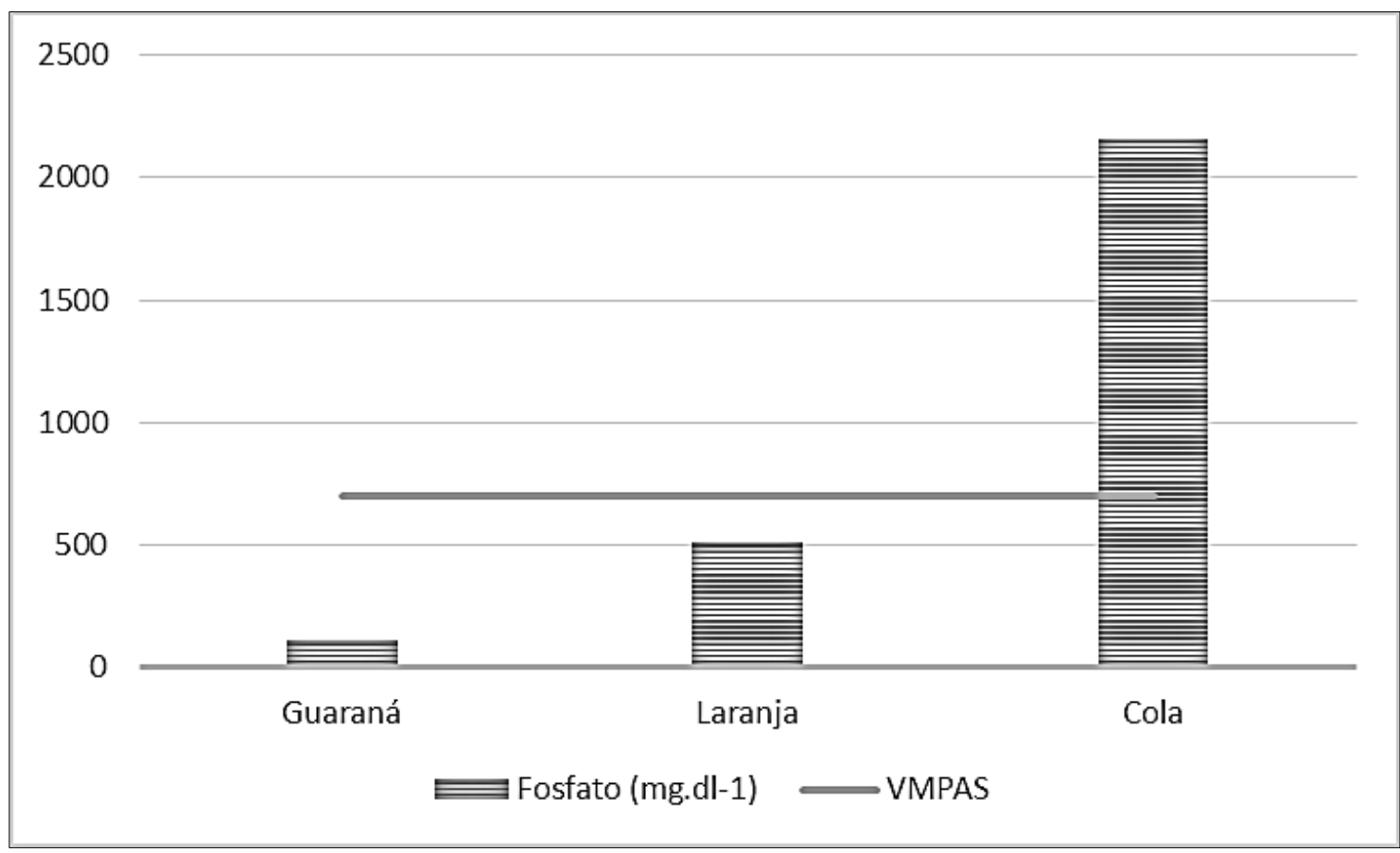

Fonte: $\mathrm{O}$ autor

Nota: VMPAS = Valor Máximo Permitido para Adultos Saudáveis.

Conforme o gráfico 3 , se comparado os resultados, em $\mathrm{mg}^{-\mathrm{dl}^{-1}}$, com o valor recomendado de ingestão diária, $700 \mathrm{mg}^{-\mathrm{dl}^{-1}}$, temos que o refrigerante do tipo cola é o único que ultrapassa o limite, apresentando alto risco por contar com concentração três vezes acima da recomendação diária. Um estudo por Dhingra et al. (2007), avaliou a relação dos níveis séricos de fósforo e cálcio com a incidência de doença cardiovascular na comunidade, contando com 3368 participantes livres de doença cardiovascular e doença renal crônica, sendo $51 \%$ do sexo feminino, e no seguimento houve 524 eventos de doença cardiovascular, o que no fim do estudo foi associado que níveis séricos do mineral corrobora com o aumento do risco de doença cardiovascular. Além disso, estudos de manipulação genética e dietética fornecem evidências in vivo para a toxicidade do fosfato afirmando que o íon poliatômico acelera o processo de envelhecimento, na qual sugerem um novo papel para o fosfato 
no envelhecimento dos mamíferos (OHNISHI; RAZZAQUE, 2010).

Segundo Noori et al. (2010), maior ingestão de fósforo na dieta estão associadas ao aumento do risco de morte em pacientes em hemodiálise mesmo após ajustes para fósforo sérico, ligantes de fosfato e ingestão dietética de proteína, energia e potássio. Por isso, dentre os três tipos de refrigerantes avaliados, guaraná é o mais adequado. A propósito, nos resultados apresentados foi levado em consideração o conteúdo total da lata do refrigerante, $350 \mathrm{~mL}$.

Diante do exposto ficou claro como alguns tipos de refrigerantes apresenta alto risco de níveis séricos e plasmáticos elevados em adultos saudáveis após uma refeição rica do mineral fósforo pelo uso de sais contendo o íon poliatômico de fosfato como aditivos nesse tipo de industrializados. Regulamentos europeus, por exemplo, permitem até 700 $\mathrm{mg} . \mathrm{L}^{-1}$ de fosfato em bebidas à base de cola; se fosse adicionado tanto fosfato, um litro de cola já forneceria $50 \%$ a $75 \%$ da dose diária recomendada de fosfato para adultos. A quantidade real de fosfato adicionada a cada litro de cola é um pouco menor, no entanto, cerca de $520 \mathrm{mg}$ (RITZ et al., 2012).

Para pacientes com DRC, nenhum dos refrigerantes é recomendado o consumo, visto que dentre os diferentes tipos os resultados (Gráfico 3) foram entre 112 a $2.156 \mathrm{mg}^{-\mathrm{dl}^{-1}}$ e a recomendação diária para portadores de DRC é de 3,5 mg.dl ${ }^{-1}$.

\section{CONSIDERAÇÕES FINAIS}

Opções de combinação para controle eficaz de hiperfosfatemia são as restrições dietéticas de fosfato, diálise adequada e ligantes de fosfato. No entanto, a obtenção de alvos de controle de fosfato é difícil e pode não ser alcançada em muitos pacientes (SHAMAN; KOWALSKI, 2016).

As amostras de refrigerantes do tipo guaraná foram as únicas que apresentaram em conformidade tanto com a legislação quanto com a recomendação da ingestão diária de fosfato, na qual indica ser o mais adequado para consumo de adultos saudáveis. Lembrando que, o consumo deste tipo de refrigerante não é potencial causador de hiperfosfatemia, porém não impede de outros problemas como obesidade pelos altos níveis de açúcares na composição.

Apesar da grande preocupação em relação ao consumo de refrigerantes ser um dos causadores da obesidade (LUDWIG et al. , 2001. APOVIAN, 2004. BASU et al., 2013. SHI, 2015. CHAVES et al., 2018. ZHENG; HUANG; ROSS JR, 2019), conclui-se que, órgãos fiscalizadores devem se atentar com outros fatores de riscos presentes na composição do produto por ser uma bebida muito consumida e com alto potencial causador de hiperfosfatemia.

\section{AGRADECIMENTOS}

Os autores agradecem a Universidade do Oeste Paulista (UNOESTE) por financiar a pesquisa e a todos do laboratório de química que contribuiu com todo o suporte técnico para a execução da parte experimental.

\section{REFERÊNCIAS}

ALONSO, M. B. C. C. Avaliação da densidade mineral óssea, conteúdo mineral ósseo e níveis séricos de cálcio, fósforo e magnésio em ratos submetidos à dieta diária de café e refrigerantes à base de cola e guaraná. 2015. 64 f. Tese (Doutorado) - Universidade Estadual de Campinas, Faculdade de Odontologia de Piracicaba, Piracicaba, SP. Disponível em: http://www.repositorio.unicamp.br/handle/ REPOSIP/288533. Acesso em: 04 ago. 2019.

APOVIAN, C. M. Sugar-sweetened soft drinks, obesity, and type 2 diabetes. Jama, v. 292, n. $8, \quad$ p. $978-979, \quad 2004$. https://doi.org/10.1001/jama.292.8.978

BNDES. O setor de bebidas no Brasil. Banco Nacional de Desenvolvimento Econômico e Social (BNDES). São Paulo, 2014.

BASU, S. et al. Relationship of soft drink consumption to global overweight, obesity, and diabetes: a cross-national analysis of 75 
countries. American journal of public health, v. 103, n. 11, p. 2071-2077, 2013. https://doi.org/10.2105/AJPH.2012.300974

BIGGS, S.; DUNN, J.; YAO, M. Beyond the sugar: Chemicals in sodas and their link to systemic diseases and oral health. 2017.

BRASIL. Lei no 6.437, de 20 de agosto de 1977: Configura infrações à legislação sanitária federal, estabelece as sanções respectivas, e dá outras providências. Diário Oficial da União, 1977.

CHAVES, O. C. et al. Soft drink consumption and body mass index in Brazilian adolescents: National Adolescent Student Health Survey.Revista Brasileira de Epidemiologia, v. 21, (Supl. 1,) p.1-13, 2018. http://dx.doi.org/10.1590/1980549720180010.supl.1

DA SILVA, A. L. A.; JUNIOR, A. I. S.; DE CASTRO, J. P.; BENTO, R. M. A. Treinamento de professores em análise instrumental espectrofotometria. CONGRESSO BRASILEIRO DE QUIMICA. 53; 2013. Rio de Janeiro/RJ. Anais [...]. Rio de Janeiro: Associação Brasileira de Química, 2013.

DHINGRA, R. et al. Relations of serum phosphorus and calcium levels to the incidence of cardiovascular disease in the community. Archives of internal medicine, v. 167, n. 9, p. 879-885, 2007. https://doi.org/10.1001/archinte.167.9.879

FELIX, L. C. M.; MEDEIROS, V. C. M.; MOLINA, V. B. C. Análise do conhecimento e consumo de alimentos fontes de fósforo por pacientes portadores de insuficiência renal crônica em tratamento dialítico. Braspen J, v. 33, n. 1, p. 15-20, 2018.

INSTITUTO ADOLFO LUTZ Normas Analíticas do Instituto Adolfo Lutz. v.1:

LOH, T. P.; SAW, S.; SETHI, S. K. Hyperphosphatemia in a 56-year-old man with hypochondrial pain. Clinical chemistry, v. 56, n. 6, p. 892-895, 2010. https://doi.org/10.1373/clinchem.2009.1368 $\underline{95}$

LUDWIG, D. S.; PETERSON, K. E.; GORTMAKER, S. L. Relation between consumption of sugar-sweetened drinks and childhood obesity: a prospective, observational analysis. The Lancet, v. 357, n. 9255, p. 505-508, 2001. https://doi.org/10.1016/S01406736(00)04041-1

MATEO, C. R. El fosfato marca la diferencia. XVI Edición del Carnaval de Química. Hablando de Ciencia. 2012. Disponível em: https://www.hablandodeciencia.com/articul os/2012/06/28/sutiles-cambios-quimicosdrasticas-consecuencias-para-la-funcion-delas-proteinas/. Acesso em: 01 ago. 2019.

MÉTODOS químicos e físicos para análise de alimentos. São Paulo: IMESP, 3. ed. 1985. p 33.

MOE, S. M. Disorders involving calcium, phosphorus, and magnesium. Primary Care: Clinics in Office Practice, v. 35, n. 2, p. 215237, 2008. https://doi.org/10.1016/j.pop.2008.01.007

MOSTELLAR, M. E.; TUTTLE, E. P. Effects of alkalosis on plasma concentration and urinary excretion of inorganic phosphate in man. The Journal of clinical investigation, $v$. 43, n. 1, p. 138-149, 1964. https://doi.org/10.1172/JCl104888

NOORI, N. et al. Association of dietary phosphorus intake and phosphorus to protein ratio with mortality in hemodialysis patients. Clinical Journal of the American Society of Nephrology, v. 5, n. 4, p. 683-692, 2010. https://doi.org/10.2215/CJN.08601209

OHNISHI, M.; RAZZAQUE, M. S.. Dietary and genetic evidence for phosphate toxicity accelerating mammalian aging. The FASEB 
Journal, v. 24, n. 9, p. 3562-3571, 2010. https://doi.org/10.1096/fj.09-152488

OLIVEIRA, P. H. D.; LUSTOSA, P. R. B.; SALES, I. C. H. Comportamento de custos como parâmetro de eficiência produtiva: uma análise empírica da companhia Vale do Rio Doce antes e após a privatização. Revista Universo Contábil, v. 3, n. 3, p. 54-70, 2007.

ORIAS, M.; MAHNENSMITH, R. L.; PERAZELLA, M. A. Extreme hyperphosphatemia and acute renal failure after a phosphorus-containing bowel regimen. American journal of nephrology, v. 19, n. 1, p. 60-63, 1999. https://doi.org/10.1159/000013427

PRINCE, M. J. et al. Hyperphosphatemic tumoral calcinosis: association with elevation of serum 1, 25-dihydroxycholecalciferol concentrations. Annals of Internal Medicine, v. 96, n. 5, p. 586-591, 1982. https://doi.org/10.7326/0003-4819-96-5-586

RITZ, E. et al. Phosphate additives in food-a health risk. Deutsches Ärzteblatt International, v. 109, n. 4, p. 49, 2012. https://doi.org/10.3238/arztebl.2012.0049

SCHAEFER, K. Unsatisfactory control of serum phosphate: Why is it so common and what can be done?. 1994.

SHAMAN, A. M.; KOWALSKI, S. R. Hyperphosphatemia management in patients with chronic kidney disease. Saudi Pharmaceutical Journal, v. 24, n. 4, p. 494505, 2016. https://doi.org/10.1016/j.jsps.2015.01.009

SHI, Z. et al. Soft drink consumption and multimorbidity among adults. Clinical nutrition ESPEN, v. 10, n. 2, p. e71-e76, 2015. https://doi.org/10.1016/i.clnesp.2015.01.001

SILVA, A. C. S.; PINHEIRO, S. V. B.; SOUTO, M. F. O. Distúrbios de cálcio e fósforo na infância. Rev Med Minas Gerais, v. 16, n. 1, p. 26-37, 2006.
SILVA, D. C. G. et al. Consumo de bebidas açucaradas e fatores associados em adultos. Ciência \& Saúde Coletiva, v. 24, p. 899-906, 2019. https://doi.org/10.1590/1413$\underline{81232018243.05432017}$

URIBARRI, J. Phosphorus homeostasis in normal health and in chronic kidney disease patients with special emphasis on dietary phosphorus intake. Seminars in dialysis, $v$. 20, n. 4, p. 295-301. 2007.https://doi.org/10.1111/j.1525139X.2007.00309.x

WILLETT, W. Eat, drink, and be healthy: the Harvard Medical School guide to healthy eating. Simon and Schuster, 2017.

ZHENG, H.; HUANG, L.; ROSS JR, W. Reducing Obesity by Taxing Soft Drinks: Tax Salience and Firms' Strategic Responses. Journal of Public Policy \& Marketing, p. 0743915619845424, 2019. https://doi.org/10.1509/jppm.17.057 